\title{
Clinical and functional characteristics of youth at clinical high-risk for psychosis who do not transition to psychosis
}

\section{Original Article}

Cite this article: Addington J et al (2019). Clinical and functional characteristics of youth at clinical high-risk for psychosis who do not transition to psychosis. Psychological Medicine 49, 1670-1677. https://doi.org/10.1017/ S0033291718002258

Received: 13 June 2018

Revised: 19 July 2018

Accepted: 2 August 2018

First published online: 4 September 2018

\section{Key words:}

Attenuated symptoms; clinical high risk; conversion; functioning; psychosis

Author for correspondence:

Jean Addington, E-mail: jmadding@ucalgary.ca

\author{
Jean Addington ${ }^{1}$, Jacqueline Stowkowy ${ }^{1}$, Lu Liu ${ }^{1}$, Kristin S. Cadenhead ${ }^{2}$, \\ Tyrone D. Cannon ${ }^{3}$, Barbara A. Cornblatt ${ }^{4}$, Thomas H. McGlashan ${ }^{5}$, \\ Diana O. Perkins ${ }^{6}$, Larry J. Seidman ${ }^{7}$, Ming T. Tsuang ${ }^{2,8}$, Elaine F. Walker ${ }^{9}$, \\ Carrie E. Bearden ${ }^{10}$, Daniel H. Mathalon ${ }^{11,12}$, Olga Santesteban-Echarri ${ }^{1}$ \\ and Scott W. Woods ${ }^{5}$ \\ ${ }^{1}$ Department of Psychiatry, Hotchkiss Brain Institute, University of Calgary, Calgary, Alberta, Canada; ${ }^{2}$ Department \\ of Psychiatry, University of California San Diego, La Jolla, California, USA; ${ }^{3}$ Department of Psychology, Yale \\ University, New Haven, CT, USA; ${ }^{4}$ Department of Psychiatry, Zucker Hillside Hospital, Queens, NY, USA; \\ ${ }^{5}$ Department of Psychiatry, Yale University, New Haven, CT, USA; ${ }^{6}$ Department of Psychiatry, University of North \\ Carolina, Chapel Hill, NC, USA; ${ }^{7}$ Department of Psychiatry, Harvard Medical School at Beth Israel Deaconess \\ Medical Center and Massachusetts General Hospital, Boston, MA, USA; ${ }^{8}$ Institute of Genomic Medicine, University \\ of California, La Jolla, CA, USA; ${ }^{9}$ Department of Psychology, Emory University, Atlanta, GA, USA; ${ }^{10}$ Departments of \\ Psychiatry and Biobehavioral Sciences and Psychology, University of California, Los Angeles, CA, USA; \\ ${ }^{11}$ Department of Psychiatry, University of California, San Francisco, USA and ${ }^{12}$ Psychiatry Service, San Francisco, \\ CA, USA
}

\begin{abstract}
Background. Much of the interest in youth at clinical high risk (CHR) of psychosis has been in understanding conversion. Recent literature has suggested that less than $25 \%$ of those who meet established criteria for being at CHR of psychosis go on to develop a psychotic illness. However, little is known about the outcome of those who do not make the transition to psychosis. The aim of this paper was to examine clinical symptoms and functioning in the second North American Prodrome Longitudinal Study (NAPLS 2) of those individuals whose by the end of 2 years in the study had not developed psychosis.

Methods. In NAPLS-2 278 CHR participants completed 2-year follow-ups and had not made the transition to psychosis. At 2-years the sample was divided into three groups - those whose symptoms were in remission, those who were still symptomatic and those whose symptoms had become more severe.

Results. There was no difference between those who remitted early in the study compared with those who remitted at one or 2 years. At 2-years, those in remission had fewer symptoms and improved functioning compared with the two symptomatic groups. However, all three groups had poorer social functioning and cognition than healthy controls.

Conclusions. A detailed examination of the clinical and functional outcomes of those who did not make the transition to psychosis did not contribute to predicting who may make the transition or who may have an earlier remission of attenuated psychotic symptoms.
\end{abstract}

\section{Introduction}

Over the past two decades, there has been an international attempt to better understand and identify the early stages of psychosis (McGorry, 2015). Reliable criteria have been developed (McGlashan et al., 2010) which has enabled researchers to prospectively follow individuals considered to be at clinical high risk (CHR) of psychosis, with the goal of being able to distinguish differences between those who go on to develop psychosis and those who do not. However, despite advances in this research, nearly two-thirds of these individuals who meet CHR criteria will not go on to develop a psychotic illness (Fusar-Poli et al., 2012a). This has led to an increase in interest regarding the outcome of CHR individuals who do not make the transition to psychosis. A recent meta-analysis has shown that over a 2-year follow-up approximately $73 \%$ of recruited CHR individuals did not convert to psychosis, and that of these individuals, about $43 \%$ fully remitted from their attenuated psychotic symptoms (APS) (Simon et al., 2013). Since this meta-analysis, a few other studies have attempted to better understand the outcome of those who do not make the transition to psychosis. Armando et al. (2015) reported that in their small sample of children aged 9-17, they found that only the non-converters who remitted from CHR status improved on functioning. Additionally, although there were no variables that predicted remission, the absence of unusual 
thought content and lower score on disorganized symptoms were related to better outcome (Armando et al., 2015). Typically, remission has referred to remission of APS severity. However, a recent publication from Korea found that when only APS was considered the remission rate was $56 \%$ but when improvement in functioning was added only $39.7 \%$ were in remission (Lee et al., 2014).

There has been some interest in better understanding the presence of poor functioning and comorbid psychopathology amongst those who do not go on to convert to psychosis. In an earlier paper with our first cohort in the North American Prodrome Longitudinal Study, we reported that there was significant poor functioning even for those who had remission of APS (Addington et al., 2011). In the OASIS study, in the UK, $71.6 \%$ had not made the transition to psychosis (Rutigliano et al., 2016). After a 6-year follow-up, $28.3 \%$ reported APS, $45.4 \%$ had a functional impairment and $56.8 \%$ had at least one co-morbid disorder at follow-up (Rutigliano et al., 2016). Interestingly if a disorder was present at baseline, $61.5 \%$ had persistence of it at follow-up. In the PACE follow-up of 2-14 years, Lin et al reported that of those who had not made the transition to psychosis, $28.3 \%$ had persistent APS, and $68 \%$ had a non-psychotic disorder, typically depression and/or anxiety (Lin et al., 2015).

The present study, the second North American Prodrome Longitudinal Study (NAPLS 2) aimed to add to the body of existing research on the outcome of individuals who do not convert to psychosis. However, we will further differentiate those who do not make a transition into three groups based on 24-month symptom ratings: (1) those in remission, determined by scores $\leqslant 2$ on all five APS on The Scale of Psychosis-risk Symptoms (SOPS); (2) symptomatic, determined by still having a rating of 3-5 on any one of the five APS on the SOPS; and (3) prodromal progression, determined by continuing to meet the Criteria of Psychosis-risk Syndromes (COPS). We will attempt to address some of the limitations of previous research in that we will include information on medications as well as provide more specific ( $v$. global) measures of social and role functioning.

We hypothesize that among the non-converter sample, those who continue to evidence APS will have increased psychopathology and poorer social, role and cognitive functioning compared with those who remit from their symptoms.

\section{Methods}

\section{Participants}

All participants are part of the second North American Prodrome Longitudinal Study (NAPLS-2). Participants in this study were help-seeking and were recruited through various resources. Most of the participants were referred from family physicians, mental health clinics, social services, and school and college counsellors. Many self-referred in response to community educational efforts. Recruitment efforts have been described in detail elsewhere (Addington et al., 2012). The NAPLS-2 sample consisted of a total of 764 youth at CHR (436 males, 328 females) and 279 healthy controls (HC) (141 males, 138 females) recruited across the eight NAPLS-2 sites. All participants were assessed with the Structured Interview for Psychosis-risk Syndromes (SIPS) (McGlashan et al., 2010) to determine if they met the COPS, i.e. one or more of the following high risk syndromes: APS syndrome (APSS); brief intermittent psychotic symptoms syndrome; or genetic risk and deterioration syndrome. Of the total 764 NAPLS-2 sample, 86 made the transition to psychosis, 390 did not complete the 2-year study (see Stowkowy et al., 2017), 10 did stay for 2 years but had minimal 2-year data and 278 CHR had not made the transition to psychosis and had completed 2 years of follow-up and thus will be the sample described in this paper. Of the 278 who completed 2 years, $66 \%$ completed all five assessments, $24 \%$ missed one assessment, $5 \%$ missed two and $5 \%$ missed three. In total $143 \mathrm{HCs}$ completed the 2-year follow-up. Participants were between 12 and 35 years of age. Exclusion criteria included meeting criteria for any current or past axis I psychotic disorder, IQ less than 70, or past or current history of a clinically significant central nervous system disorder. Exclusion criteria for HCs was a first-degree relative with a current or past psychotic disorder.

\section{Measures}

The Structured Interview for SIPS (McGlashan et al., 2010) was used to determine whether an individual met COPS criteria. The Scale of Psychosis-risk Symptoms (SOPS) was used to rate the severity of APS. The SOPS consists of 19 items in four symptom domains (i.e. positive, negative, general, and disorganized symptoms).

The Structured Clinical Interview for DSM-IV (SCID) (First et al., 1995) was used to determine the presence of current and past psychiatric diagnoses, including conversion to a psychotic disorder. Conversion to psychosis was determined by meeting the Presence of Psychotic Symptoms (POPS) (McGlashan et al., 2010) criteria. The POPS require that at least one of the five SOPS APS had reached a psychotic level of intensity (rated 6) for a frequency of less than or equal to $1 \mathrm{~h}$ per day for 4 days per week, or that psychotic symptoms were seriously impacting functioning (e.g. disorganizing or dangerous to self or others).

Four different clinical outcomes were determined at each of the follow-up assessments. These were: (1) remission is defined as remission from all CHR syndromes, i.e. participants had to have scores of 2 or less on all five positive symptoms on the SOPS scale; (2) symptomatic but not currently meeting criteria for a prodromal risk syndrome. This means that participants should have ratings of 3-5 on any one of the five positive symptoms on the SOPS but the symptoms had neither worsened or begun in the previous 12 months; (3) prodromal progression which meant that the participant at a given assessment would currently meet criteria for APSS; that is one of the five positive symptoms had to have begun or increased in the previous 12 months and (4) psychotic which would mean that the participant currently met criteria for a psychotic disorder or evidencing scores of 6 on one or more positive symptoms of the SOPS, i.e. one of the positive symptoms had reached psychotic intensity (McGlashan et al., 2010).

The functional outcome measures included the Global Functioning-Social (GF:S) and Role (GF:R) scales. Both scales were developed specifically to address functioning in youth at risk of psychosis and are psychometrically sound, with good construct validity (Cornblatt et al., 2007).

For cognition tasks from the MATRICS battery (Nuechterlein et al., 2008) that reflected areas of cognition most often seen as problematic in CHR such as speed of processing, verbal learning and working memory (Fusar-Poli et al., 2012b; Seidman et al., 2016) were chosen. These include Trails A, letter-number span, the BACS and the Hopkins Verbal Learning Test. 


\section{Procedures}

Both CHR individuals and HCs were recruited for the study, which was approved by the Institutional Review Boards of all eight NAPLS-2 sites. Written informed consent, including parental consent, was obtained from all adult participants and parents/ guardians of minors.

After the initial screening assessment that included administering the SCID and the SIPS, vignettes were developed for each CHR participant to obtain a consensus decision on meeting COPS criteria. The APS rated on the SOPS are described at length and include both recent and longstanding symptoms. The vignettes are written so that raters from all eight sites can review the information under each symptom category and provide a reliable rating. Once approved at the site level, the vignette is presented on a conference call for a consensus decision on the symptom ratings as well as the diagnosis. The NAPLS- 2 consensus call, chaired by JA, was held once a week and attended by the clinical raters from each of the eight sites. Submitted vignettes are individually reviewed and a consensus must be reached on each symptom rating, diagnosis and ultimate admission into the study. Clinical raters were experienced research clinicians. Gold standard posttraining agreement on determining the prodromal diagnoses was excellent $(\kappa=0.90)$ (Addington et al., 2012). Diagnostic interviews at all sites were conducted by trained raters. Data were collected at five-time points: baseline, 6-, 12-, 18- and 24-month follow-up.

\section{Statistical analysis}

One-way ANOVA was used to compare groups on all continuous variables. $\chi^{2}$ tests were used to compare the groups on SCID diagnoses at both baseline and 24 months.

The analysis of medication differences was performed using SAS 9.4. We used the generalized estimating equations (GEE) models to determine the differences in the use of antipsychotics, antidepressants and anxiolytics across all assessments (baseline, 6, 12,18 and 24 months) for four remitter groups (remission at 6 months, 12 months, 18 months and 24 months) as well as for the overall 3 groups (in remission, symptomatic and prodromal progression). The same analyses were used to compare the overall three groups on the use of non-pharmacological treatments.

\section{Results}

Of the total NAPLS 2 sample, 278 CHR had not made the transition to psychosis and had completed 2 years of follow-up. This is the sample described in this paper. Among these participants, 110 $(39.57 \%)$ were in remission, $93(33.45 \%)$ symptomatic, and 75 (26.98\%) continued to meet criteria for APSS and thus are experiencing prodromal progression. Further examination of these groups across time showed that the symptomatic group was symptomatic across all follow-up assessments and that the prodromal progression group tended to meet prodromal progression or be symptomatic across all follow-up assessments. However, those in remission at 24 months could be divided into those who remitted at 6 months, at 12 months, 18 months and then 24 months. Once an individual remitted they typically remained in remission. We did, however, compare these four remission groups on all the variables under study. Differences were that the 12-month remitters had significantly lower ratings on the SOPS total positive symptoms compared with those who remitted at 24 months at baseline $(p<0.05)$ and at 24 months $(p<0.01)$ and at 24 months anxiety disorders were more common in those who remitted at 18 and 24 months. See online Supplementary Tables S1 and S2. Thus, since there were not many differences among the remitters in symptoms, cognition, functioning and other disorders for all further analyses we have the remitters as one group.

\section{Comparison of in-remission, symptomatic and prodromal progression groups}

Demographics are presented in Table 1 . There were no significant differences between the groups on any demographic variables.

We compared the three groups on symptoms at baseline and at 2-years. To avoid multiple comparisons, we only examined individual SOPS symptoms if the groups differed on any of the total scores. At baseline the prodromal progression group had significantly higher ratings on unusual thought content compared with the remission group and the symptomatic group had significantly higher ratings on suspiciousness compared with the remission group. Both the symptomatic and prodromal progression groups had significantly higher ratings on total positive symptoms than the remission group. The groups did not differ on any other of the SOPS symptom domains. Comparison of the three groups at 24 months demonstrated that both the symptomatic and prodromal progression groups had significantly higher ratings not only on positive symptoms as would be expected but on all SOPS domains. The remission group had significantly less total negative symptoms, and lower ratings on avolition and decreased expression of emotion than the other groups. The symptomatic and prodromal progression groups did not differ on any of the general symptoms or disorganized symptoms and received more severe ratings than the remission group. The one exception was impaired personal hygiene that was not a problem in any group. See Table 2.

Lifetime and current DSM-IV diagnoses were assessed at baseline and current diagnoses at 24 months. The most common diagnoses in all groups were depression and anxiety. The groups did not differ on lifetime diagnoses and the only diagnoses that the groups differed on at baseline was anxiety and post-traumatic stress disorder (PTSD). At the 2-year follow-up, the remission group had significantly fewer cases of depression and the symptomatic groups significantly more cases of anxiety. These results are presented in Table 3.

See online Supplementary Table S3 for frequencies of all diagnoses lifetime, baseline and 24 months. In addition, a comparison of DSM-IV diagnoses between the HCs and remitted participants revealed that those who had remitted in terms of APS still had increased comorbid diagnoses compared with HCs. See online Supplementary Table S4.

Table 4 shows that the groups did not differ at baseline on either role or social functioning nor at 24 months in role functioning. The remission group had improved social functioning at 24 months. Online Supplementary Table S5 shows that the groups did not differ on any of the cognitive tasks.

Since the remission group typically had improved functioning relative to the symptomatic and prodromal progression group, the three CHR groups were compared with the HC on social, role and neurocognitive functioning. All three CHR groups had significantly poorer ratings on both social and role functioning compared with HC. For neurocognition, the prodromal progression group had poorer ratings on 3 of the 4 neurocognitive tasks compared with the $\mathrm{HC}$ and on the 4 th task, the remission and symptomatic groups had poorer scores. See Table 5. 
Table 1. Demographic information

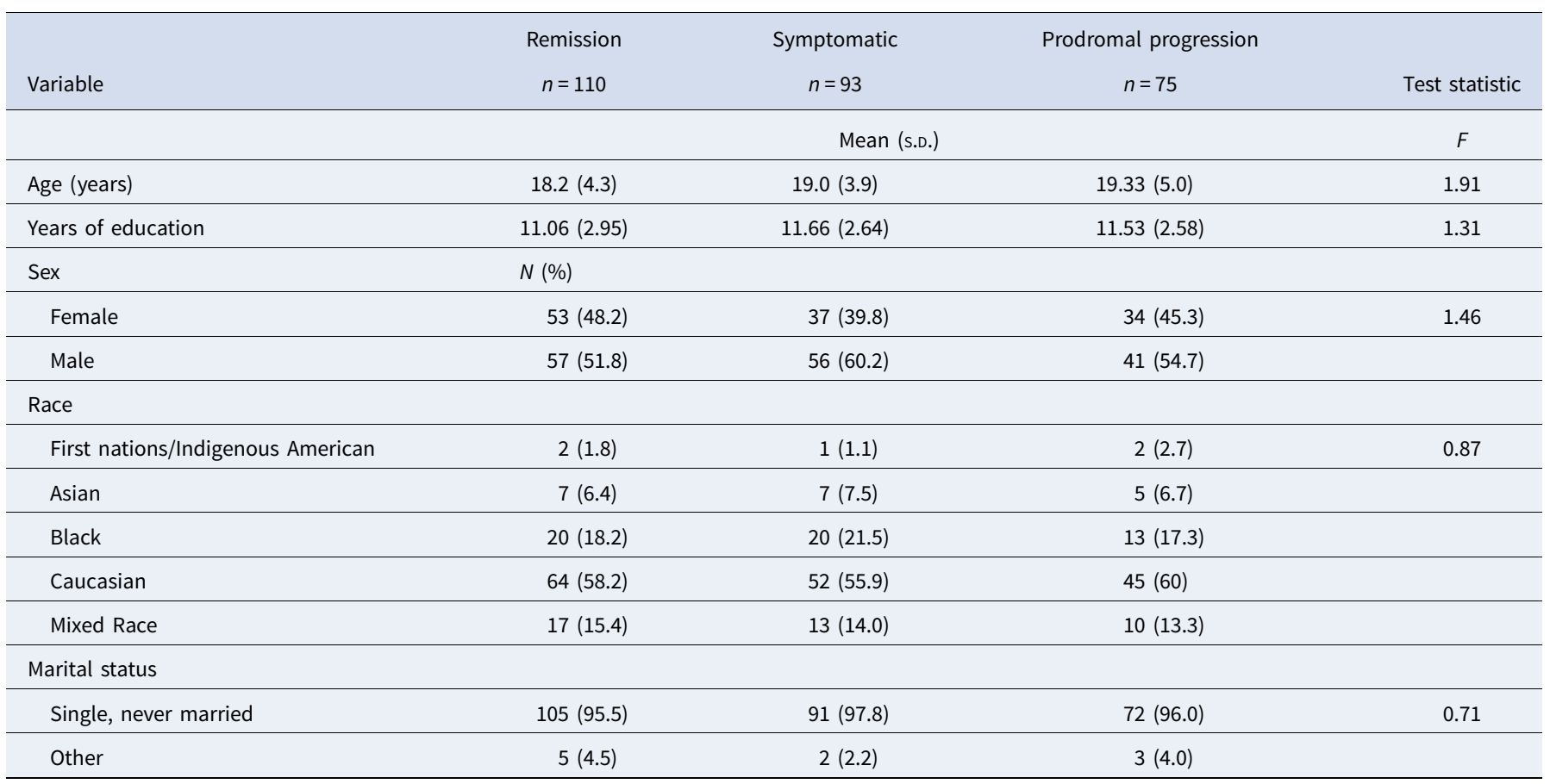

\section{Treatment comparisons}

First, the 3 CHR groups were compared on their use of medication (antipsychotics, antidepressants and anxiolytics) over time. The remission group (remission at 6 months, 12 months, 18 months and 24 months) were also compared on their use of medication. There were no significant differences between any of the groups in their use of medication over the 2 years in the study. These results are presented in online Supplementary Tables S6 and S7. Psychosocial treatments included individual, family and group therapies, case-management and school counselling. There were no significant differences between any of the groups in their use of psychosocial treatments. See online Supplementary Table S8.

\section{Discussion}

Since the majority of CHR participants do not make the transition to psychosis, the purpose of this paper was to report on youth in the NAPLS 2 project who completed 2 years in the study but who did not make the transition to psychosis. This may be becoming more important since in the literature there seems to be a trend for declining transition rates. (Fusar-Poli et al., 2012a; Riecher-Rossler and Studerus, 2017) Furthermore, since amongst those who do not make the transition there is a range of specific symptomatic outcomes, we wanted to examine sub-groups that included those who had a complete remission of APS, those who continued to have symptoms and those whose symptoms seemed to be increasing in severity. Of our sample that completed the 2-year follow-up without a transition approximately one third fell into each of these three groups. Our rates for the remission of APS for those who completed the study fit with other reports in the literature.

We first explored those who were in remission at 2-years. It seemed possible that perhaps there would be something we could learn about those who had a complete remission from
APS at 6 or even 12 months compared with those whose remission occurred later in the project but we were unable to find any clinical or functional variable that really differentiated these groups. Most notable was that the later remitters evidenced more anxiety disorders at 24 months which might have accounted for the longer time to remission. Those who remained symptomatic or whose symptoms increased tended to have higher ratings on APS at baseline and 2-years which is not surprising. They did, however, have increased symptoms overall, i.e. negative, disorganized and general symptoms, compared with remitters at 2 -years, as well as more anxiety and mood diagnoses. This suggests that they are generally more symptomatic overall compared with those who remit.

An examination of social and role functioning demonstrated that although the remission group had somewhat improved social functioning at 2 years compared with the other CHR groups they were still functioning below the HC. Interestingly all CHR groups continued to have poorer role functioning than the $\mathrm{HC}$. This suggests that perhaps poorer social and functioning may be independent of attenuated symptoms in those at CHR. A recent meta-analysis supports this possibility in that poor functioning in adolescence, in terms of education and employment accomplishments, was predictive of later CHR status (Fusar-Poli et al., 2017).

For neurocognitive functioning, the speed of processing and working memory seemed to be the key functions that differentiated the symptomatic CHR groups from the others. In both schizophrenia and in those at CHR speed of processing and memory are key common neurocognitive deficits (Seidman et al., 2016). However, recent publications have demonstrated that working memory and/or speed of processing can be predictive of later transition to psychosis, suggesting that these are the cognitive functions most likely to be impaired for those at $\mathrm{CHR}$ (Cornblatt et al., 2015; Addington et al., 2016; Cannon et al., 2016) and perhaps ones that could be addressed in terms of remediation (Choi et al., 2017). 
Table 2. Group comparisons of symptoms at baseline \& 24 months

\begin{tabular}{|c|c|c|c|c|}
\hline Variable & In Remission $n=110$ & Symptomatic $n=93$ & Prodromal progression $n=75$ & Test statistic \\
\hline & & Mean (s.D.) & & $F$ \\
\hline \multicolumn{5}{|l|}{ Baseline comparisons } \\
\hline Total positive symptoms & $10.70(4.34)$ & $12.41(3.62)^{a}$ & $12.23(4.13)^{\mathrm{a}}$ & $5.40^{\star \star}$ \\
\hline P1 - Unusual thought content & $2.91(1.48)$ & $3.26(1.13)$ & $3.61(1.36)^{\mathrm{a}}$ & $6.24^{\star \star}$ \\
\hline P2 - Suspiciousness & $2.30(1.57)$ & $2.99(1.28)^{a}$ & $2.71(1.56)$ & $5.59^{\star \star}$ \\
\hline P3 - Grandiose ideas & $0.91(1.30)$ & $1.19(1.35)$ & $1.09(1.33)$ & 1.20 \\
\hline P4 - Perceptual abnormalities & $3.00(1.51)$ & $3.22(1.26)$ & $3.25(1.55)$ & 0.87 \\
\hline P5 - Disorganized thought & $1.58(1.41)$ & $1.75(1.34)$ & $1.56(1.53)$ & 0.50 \\
\hline Total negative symptoms & $11.67(6.02)$ & $12.26(6.13)$ & $11.81(5.93)$ & 0.25 \\
\hline Total general symptoms & $8.72(4.36)$ & $9.39(4.36)$ & $8.75(4.38)$ & 0.70 \\
\hline Total disorganized symptoms & $4.62(3.04)$ & $5.29(3.58)$ & $5.48(3.20)$ & 1.94 \\
\hline \multicolumn{5}{|l|}{24 month comparisons } \\
\hline Total positive symptoms & $2.70(2.10)$ & $8.58(3.57)^{a}$ & $9.85(4.24)^{a, b}$ & $130.52^{\star \star \star \star}$ \\
\hline P1 - Unusual thought content & $0.70(0.84)$ & $2.27(1.44)^{\mathrm{a}}$ & $2.76(1.65)^{a, b}$ & $65.24^{\star \star \star \star}$ \\
\hline P2 - Suspiciousness & $0.65(0.80)$ & $2.39(1.18)^{a}$ & $2.43(1.50)^{\mathrm{a}}$ & $77.84^{\star \star \star \star}$ \\
\hline P3 - Grandiose ideas & $0.21(0.54)$ & $0.87(1.16)^{\mathrm{a}}$ & $0.91(1.24)^{a}$ & $15.52^{\star \star \star \star}$ \\
\hline P4 - Perceptual abnormalities & $0.58(0.81)$ & $1.84(1.45)^{\mathrm{a}}$ & $2.59(1.67)^{\mathrm{a}, \mathrm{b}}$ & $55.83^{\star \star \star \star}$ \\
\hline P5 - Disorganized thought & $0.56(0.77)$ & $1.22(1.09)^{\mathrm{a}}$ & $1.17(1.11)^{\mathrm{a}}$ & $13.82^{\star \star \star \star}$ \\
\hline Total negative symptoms & $5.99(5.41)$ & $8.84(6.10)^{a}$ & $9.19(5.39)^{\mathrm{a}}$ & $9.49^{\star \star \star \star}$ \\
\hline N1 - Social anhedonia & $1.43(1.63)$ & $2.01(1.76)^{a}$ & $1.69(1.53)$ & $3.15^{\star}$ \\
\hline N2 - Avolition & $1.25(1.44)$ & $1.94(1.60)^{\mathrm{a}}$ & $2.19(1.74)^{\mathrm{a}}$ & $8.99^{\star \star \star \star}$ \\
\hline N3 - Expression of emotion & $0.66(1.12)$ & $1.00(1.44)$ & $0.96(1.23)$ & 2.14 \\
\hline N4 - Decreased exp. of emo. \& self & $0.49(0.93)$ & $1.01(1.40)^{\mathrm{a}}$ & $0.97(1.46)^{\mathrm{a}}$ & $5.37^{\star \star}$ \\
\hline N5 - Decreased ideational richness & $0.55(0.92)$ & $0.66(0.96)$ & $0.84(1.04)$ & 2.09 \\
\hline N6 - Occupational functioning & $1.61(2.17)$ & $2.23(2.15)$ & $2.53(2.28)^{\mathrm{a}}$ & $4.35^{\star}$ \\
\hline Total general symptoms & $3.47(3.43)$ & $6.72(3.94)^{a}$ & $7.73(4.68)^{\mathrm{a}}$ & $30.26^{\star \star \star \star}$ \\
\hline G1 - Sleep disturbance & $1.18(1.45)$ & $1.73(1.45)^{\mathrm{a}}$ & $2.20(1.74)^{a}$ & $10.05^{\star \star \star \star}$ \\
\hline G2 - Dysphoric mood & $1.17(1.34)$ & $2.39(1.56)^{a}$ & $2.71(2.06)^{\mathrm{a}}$ & $23.75^{\star \star \star \star}$ \\
\hline G3 - Motor disturbances & $0.20(0.56)$ & $0.53(0.86)^{a}$ & $0.52(0.88)^{\mathrm{a}}$ & $6.09^{\star \star}$ \\
\hline G4 - Impaired tol. to normal stress & $0.92(1.30)$ & $2.08(1.73)^{\mathrm{a}}$ & $2.31(1.83)^{\mathrm{a}}$ & $20.92^{\star \star \star \star}$ \\
\hline Total disorganized symptoms & $2.15(2.10)$ & $3.90(2.78)^{a}$ & $4.40(3.13)^{\mathrm{a}}$ & $19.43^{\star \star \star \star}$ \\
\hline D1 - Odd behaviour or appearance & $0.36(0.75)$ & $0.76(1.10)^{\mathrm{a}}$ & $0.64(1.00)$ & $4.78^{\star \star}$ \\
\hline D2 - Bizarre thinking & $0.13(0.47)$ & $0.69(0.92)^{a}$ & $0.84(1.19)^{\mathrm{a}}$ & $18.15^{\star \star \star \star}$ \\
\hline D3 - Trouble with focus and atten. & $1.26(1.25)$ & $1.88(1.18)^{\mathrm{a}}$ & $2.20(1.29)^{a}$ & $13.85^{\star \star \star \star}$ \\
\hline D4 - Impairment in personal hygiene & $0.39(0.79)$ & $0.57(1.10)$ & $0.72(1.30)$ & 2.24 \\
\hline
\end{tabular}

${ }^{\text {a }}$ Significantly different from remission group.

${ }^{\mathrm{b}}$ Significantly different from symptomatic group.

${ }^{\star} p<0.05,{ }^{\star \star} p<0.01,{ }^{\star \star \star \star} p<0.0001$.

Thus, the more severe the APS the more likely there was increased general symptoms, the presence of DSM-IV mood or anxiety disorders, poorer social functioning and poorer neurocognitive functioning. Interestingly, we did not see many differences between the prodromal progression group and the symptomatic group. The key difference was that the prodromal progression group had marginally increased APS at follow-up and the symptomatic group had more anxiety. Since the groups did not differ at baseline it is possible that the groups only differed in the stability of their APS rather than the prodromal progression group being the more severe of the two symptomatic groups. The symptomatic group continues to present with APS throughout the 2 years whereas for the prodromal progression group, there was more evidence of fluctuating symptoms. In order to meet prodromal criteria at 24 months, for some participants, there may have been an increase in symptoms over time, for others perhaps a new 
Table 3. Group comparisons of DSM-IV disorders

\begin{tabular}{|c|c|c|c|c|}
\hline Variable & In remission & Symptomatic & Prodromal progression & $\chi^{2}$ \\
\hline Lifetime diagnoses at baseline & $N=110(\%)$ & $N=93(\%)$ & $N=75(\%)$ & \\
\hline Any depression disorders & $36(32.7)$ & $28(30.4)$ & $31(41.3)$ & 2.38 \\
\hline Post-traumatic stress disorder & $1(0.9)$ & $3(1.1)$ & $2(2.7)$ & 1.43 \\
\hline Any anxiety disorder & $20(18.2)$ & $29(31.5)$ & $18(24.0)$ & 4.87 \\
\hline Attention-deficit hyperactivity disorder & $14(12.7)$ & $10(10.9)$ & $9(12.0)$ & 0.17 \\
\hline Other disorders & $41(37.2)$ & $34(36.9)$ & $31(41.4)$ & 3.77 \\
\hline \multicolumn{5}{|l|}{ Diagnoses at baseline } \\
\hline Any depression disorders & $33(30.0)$ & $32(34.8)$ & $26(34.7)$ & 0.67 \\
\hline Post-traumatic stress disorder & $0(0.0)$ & $0(0.0)$ & $5(6.7)$ & $13.71^{\star \star}$ \\
\hline Any anxiety disorder & $30(27.3)$ & $50(54.3)$ & $34(29.8)$ & $15.91^{\star \star \star \star}$ \\
\hline Attention-deficit hyperactivity disorder & $17(15.5)$ & $16(17.4)$ & $10(13.3)$ & 0.52 \\
\hline Other disorders & $39(35.5)$ & $30(32.7)$ & $27(34.5)$ & 4.04 \\
\hline Diagnoses at 24 months & $N=100(\%)$ & $N=84(\%)$ & $N=63(\%)$ & \\
\hline Any depression disorder & $21(21.0)$ & $26(31.0)$ & $25(39.7)$ & $6.73^{\star}$ \\
\hline Post-traumatic stress disorder & $1(1.0)$ & $0(0.0)$ & $3(4.8)$ & 5.53 \\
\hline Any anxiety disorder & $25(25.0)$ & $37(44.0)$ & $24(38.1)$ & $7.70^{\star}$ \\
\hline Attention-deficit hyperactivity disorder & $11(11.0)$ & $15(17.9)$ & $4(6.3)$ & 4.68 \\
\hline Other disorders & $21(21.0)$ & $20(23.9)$ & $34(54.0)$ & 11.74 \\
\hline
\end{tabular}

Table 4. Group comparisons of baseline and 24 month social and role functioning

\begin{tabular}{|c|c|c|c|c|}
\hline Variable & In remission & Symptomatic & Prodromal progression & Test statistic \\
\hline & \multicolumn{3}{|c|}{ Mean (s.D.) } & $F$ \\
\hline Baseline comparisons & $n=110$ & $n=93$ & $n=75$ & \\
\hline Global functioning: Social & $6.16(1.66)$ & $6.04(1.51)$ & $6.35(1.47)$ & 0.79 \\
\hline Global functioning: Role & $6.22(2.12)$ & $6.16(2.22)$ & $6.01(2.23)$ & 0.20 \\
\hline 24 month comparisons & $n=109$ & $n=91$ & $n=75$ & \\
\hline Global functioning: Social & $7.20(1.51)$ & $6.56(1.52)^{\mathrm{a}}$ & $6.68(1.36)^{\mathrm{a}}$ & $5.37^{\star \star}$ \\
\hline Global functioning: Role & $6.68(2.33)$ & $6.42(2.55)$ & $5.89(2.39)$ & 2.35 \\
\hline
\end{tabular}

${ }^{a}$ Significantly different from remission group.

${ }^{\star \star} p<0.01$.

symptom developed and for others there would have been some improvement and then a return to a previous level.

It has been suggested that the initial presentation of $\mathrm{CHR}$ symptoms might actually be predictive of other disorders (van and Guloksuz, 2017). However, although these CHR individuals do present with a range of other disorders, in particular, mood and anxiety, this does not seem to be the case in this data set (Webb et al., 2015; Woods et al., 2018) or in in other samples (Lin et al., 2015; Fusar-Poli et al., 2016). Lin et al in their longitudinal study of non-transitioned cases reported in their follow-up period $68 \%$ experienced a non-psychotic disorder and that $52 \%$ continued to experience a persistent or recurrent disorder (Lin et al., 2015). Thus, as a general summary it seems as if, at least clinically, after presenting with a prodromal syndrome those who do not make the transition to psychosis are on a continuum of severity of APS, that is accompanied by, although to a lesser degree, severity of poor social, role and neurocognitive functioning. Of course, it is possible that individuals in the symptomatic or prodromal progression groups may experience a later transition, even though most transitions occur within the first 2 years there are reports of later transitions (Cannon et al., 2008; Nelson et al., 2013).

Another consideration is that these individuals who remain symptomatic fit with the psychosis proneness- persistenceimpairment model proposed by van Os et al. (2009). Our symptomatic and prodromal progression individuals may well be similar to those described as initially presenting with a transitory developmental expression of psychosis that becomes abnormally persistent and subsequently clinically relevant. In this model, persistence depends on the degree of environmental risk 
Table 5. Social and role functioning and neurocognition comparisons between groups and HC's at 24-months

\begin{tabular}{|c|c|c|c|c|c|}
\hline Variable & $\mathrm{HCs} n=143^{\mathrm{a}}$ & In remission $n=110^{\mathrm{a}}$ & Symptomatic $n=93^{a}$ & Prodromal progression $n=75^{a}$ & Test statistic \\
\hline & & & Mean (s.D.) & & $F$ \\
\hline \multicolumn{6}{|l|}{ Functioning } \\
\hline GF: Social & $8.73(0.90)$ & $7.20(1.51)^{b}$ & $6.56(1.52)^{b, c}$ & $6.68(1.36)^{b, c}$ & $70.21^{\star \star \star \star}$ \\
\hline GF: Role & $8.62(0.97)$ & $6.68(2.33)^{b}$ & $6.42(2.55)^{b}$ & $5.89(2.39)^{\mathrm{b}}$ & $39.99^{\star \star \star \star}$ \\
\hline \multicolumn{6}{|l|}{ Neurocognition } \\
\hline TMT A & $24.15(7.68)$ & $25.44(8.89)$ & $26.75(9.98)$ & $30.57(19.90)^{b, c}$ & $4.54^{\star \star}$ \\
\hline BACS & $66.89(13.78)$ & $61.69(12.64)^{b}$ & $61.97(15.46)$ & $59.21(15.53)^{b}$ & $5.07^{\star \star}$ \\
\hline HVLT TOTAL & $28.67(3.86)$ & $26.63(5.03)^{b}$ & $26.73(4.78)^{b}$ & $27.16(3.93)$ & $5.28^{\star \star \star}$ \\
\hline LNS & $16.85(3.17)$ & $15.67(3.44)$ & $15.44(3.72)^{\mathrm{b}}$ & $15.42(3.70)^{\mathrm{b}}$ & $4.21^{\star \star}$ \\
\hline
\end{tabular}

HCs, healthy controls; TMT, Trail Making Test; LNS, Letter-Number Span; BACS, Brief Assessment of Cognition in Schizophrenia; HVLT, Hopkins Verbal Learning Test.

${ }^{a} n$ may not add up for each measure due to missing data.

${ }^{\mathrm{b}}$ Significantly different from healthy control group.

${ }^{\mathrm{c}}$ Significantly different from in remission group.

${ }^{\star \star} p \leqslant 0.05 ;{ }^{\star \star \star} p \leqslant 0.001 ;{ }^{\star \star \star \star} p<0.0001$.

to which the person is additionally exposed. Interestingly, in our sample we observed increased cannabis use, trauma and perceived discrimination compared with $\mathrm{HC}$ that did not necessarily predict transition to psychosis (Addington et al., 2013; Saleem et al., 2013; Buchy et al., 2015; Stowkowy et al., 2016).

The strength of this paper is that we could examine in a large cohort over a 2-year period a range of clinical outcomes for those who did not make the transition to psychosis. These clinical outcome groups were compared on a range of clinical and functional outcomes as well as treatment. There are several limitations to this study. First, the sample was only followed for 2 years which is typical of many other studies but to better address the issue of non-transition longer follow-ups are required. We do not know if once participants are no longer being followed if there would be a change in clinical outcome. Monitoring is often helpful for people especially knowing they have immediate contact should they experience a change. Secondly, it is possible that over the course of 2 years with dropouts that more of the healthy people might have dropped out. In a recent publication (Stowkowy et al., 2017) examining in detail dropouts from the NAPLS-2 project, we were unable to observe any clinical, functional or demographic variables that might indicate the likelihood of dropping out. Furthermore, our examinations of SOPS ratings suggested that at the time of dropout, dropouts had neither more nor less severe SOPS symptoms, ruling out the possibility that these CHR individuals leave the study because of either increased or improved symptoms. Thirdly, our first assessment occurred at 6 months it is possible that there might be a small subgroup of those who were in remission by 6 months who had a speedier remission and who may have improved ratings on the functional measures. Fourthly, we are unable to determine with confidence whether our prodromal progression group were given this designation due to an increase in severity or due to the appearance of a new symptom. Some participants had some improvement and then later had an increase in the symptoms. Fifthly, our comparison of the different groups was based on clinical or functional variables. There may be biological markers that might differentiate these different outcome groups more precisely and in a more meaningful way. Finally, we chose to pre-define our groups on clinical status at 2-years. It is possible that alternative approaches such as statistically identifying sub-groups with latent class analyses or machine learning may offer more information about the nature of CHR syndromes. However, this current approach is more readily translatable into real-world settings.

In conclusion, detailed examination of clinical and functional outcomes of those who by 2-years do not make the transition to psychosis does not contribute to predicting who may make the transition to psychosis or who may have an earlier remission of APS. It is possible that there are other factors that might help this distinction but based on our current data it appears as if those who present with a prodromal syndrome of APS have an outcome that is on a continuum of severity. The implications are that this is a group that requires treatment albeit at different levels of intensity that would address the attenuated symptoms, mood and/or anxiety and functioning.

Supplementary material. The supplementary material for this article can be found at https://doi.org/10.1017/S0033291718002258.

Acknowledgements. This study was supported by the National Institute of Mental Health [grantU01MH081984 to Dr Addington; grants U01 MH081928; P50 MH080272; Commonwealth of Massachusetts SCDMH82101008006 to Dr Seidman; grants R01 MH60720, U01 MH082022, and K24 MH76191 to Dr Cadenhead; grantU01MH081902 to Dr Cannon; P50MH066286 (Prodromal Core) to Dr Bearden; grant U01MH082004 to Dr Perkins; grant U01MH081988 to Dr Walker; grant U01MH082022 to Dr Woods; and UO1MH081857-05 grant to Dr Cornblatt]. The NIMH had no further role in study design; in the collection, analysis, and interpretation of data; in the writing of the report; and in the decision to submit the paper for publication

\section{Conflict of interest. None.}

Ethical standards. The authors assert that all procedures contributing to this work comply with the ethical standards of the relevant national and institutional committees on human experimentation and with the Helsinki Declaration of 1975, as revised in 2008.

\section{References}

Addington J, Cornblatt BA, Cadenhead KS, Cannon TD, McGlashan TH, Perkins DO, Seidman LJ, Tsuang MT, Walker EF, Woods SW and Heinssen R (2011) At clinical high risk for psychosis: outcome for nonconverters. American Journal of Psychiatry 168, 800-805.

Addington J, Cadenhead KS, Cornblatt BA, Mathalon DH, McGlashan TH, Perkins DO, Seidman LJ, Tsuang MT, Walker EF, Woods SW, Addington JA and Cannon TD (2012) North American prodrome 
Longitudinal Study (NAPLS 2): overview and recruitment. Schizophrenia Research 142, 77-82.

Addington J, Stowkowy J, Cadenhead KS, Cornblatt BA, McGlashan TH, Perkins DO, Seidman LJ, Tsuang MT, Walker EF, Woods SW and Cannon TD (2013) Early traumatic experiences in those at clinical high risk for psychosis. Early Intervention in Psychiatry 7, 300-305.

Addington J, Liu L, Perkins DO, Carrion RE, Keefe RS and Woods SW (2016) The role of cognition and social functioning as predictors in the transition to psychosis for youth with attenuated psychotic symptoms. Schizophrenia Bulletin 43, 57-63.

Armando M, Pontillo M, De CF, Mazzone L, Monducci E, Lo CN, Santonastaso O, Pucciarini ML, Vicari S, Schimmelmann BG and Schultze-Lutter F (2015) Twelve-month psychosis-predictive value of the ultra-high risk criteria in children and adolescents. Schizophrenia Research 169, 186-192.

Buchy L, Cadenhead KS, Cannon TD, Cornblatt BA, McGlashan TH, Perkins DO, Seidman LJ, Tsuang MT, Walker EF, Woods SW, Heinssen R, Bearden CE, Mathalon D and Addington J (2015) Substance use in individuals at clinical high risk of psychosis. Psychological Medicine 45, 2275-2284.

Cannon TD, Cadenhead K, Cornblatt B, Woods SW, Addington J, Walker E, Seidman LJ, Perkins D, Tsuang M, McGlashan $T$ and Heinssen R (2008) Prediction of psychosis in youth at high clinical risk: a multisite longitudinal study in North America. Archives of General Psychiatry 65, 28-37.

Cannon TD, Yu C, Addington J, Bearden CE, Cadenhead KS, Cornblatt BA, Heinssen R, Jeffries CD, Mathalon DH, McGlashan TH, Perkins DO, Seidman LJ, Tsuang MT, Walker EF, Woods SW and Kattan MW (2016) An individualized risk calculator for research in prodromal psychosis. American Journal of Psychiatry 173, 980-988.

Choi J, Corcoran CM, Fiszdon JM, Stevens M, Javitt DC, Deasy M, Haber LC, Dewberry MJ and Pearlson GD (2017) Pupillometer-based neurofeedback cognitive training to improve processing speed and social functioning in individuals at clinical high risk for psychosis. Psychiatric. Rehabilitation Journal 40, 33-42.

Cornblatt BA, Auther AM, Niendam T, Smith CW, Zinberg J, Bearden CE and Cannon TD (2007) Preliminary findings for two new measures of social and role functioning in the prodromal phase of schizophrenia. Schizophrenia Bulletin 33, 688-702.

Cornblatt BA, Carrion RE, Auther A, McLaughlin D, Olsen RH, John M and Correll CU (2015) Psychosis prevention: a modified clinical high risk perspective from the recognition and prevention (RAP) program. American Journal of Psychiatry 172, 986-994.

First M, Spitzer RL, Gibbon M, Williams B and Williams JBW (1995) Structured Clinical Interview for DSM-IV Axis I Disorders, Patient Edition. Biometrics Research Department, New York State Psychiatric Institute, New York: New York.

Fusar-Poli P, Bonoldi I, Yung AR, Borgwardt S, Kempton MJ, Valmaggia L, Barale F, Caverzasi E and McGuire P (2012a) Predicting psychosis: meta-analysis of transition outcomes in individuals at high clinical risk. Archives of General Psychiatry 69, 220-229.

Fusar-Poli P, Deste G, Smieskova R, Barlati S, Yung AR, Howes O, Stieglitz RD, Vita A, McGuire P and Borgwardt S (2012b) Cognitive functioning in prodromal psychosis: a meta-analysisCognitive functioning in prodromal psychosis. Archives of General Psychiatry 69, 562-571.

Fusar-Poli P, Rutigliano G, Stahl D, Davies C, De MA, Ramella-Cravaro V, Bonoldi I and McGuire P (2016) Long-term validity of the At Risk Mental State (ARMS) for predicting psychotic and non-psychotic mental disorders. European Psychiatry 42, 49-54.

Fusar-Poli P, Tantardini M, De SS, Ramella-Cravaro V, Oliver D, Kingdon J, Kotlicka-Antczak M, Valmaggia L, Lee J, Millan MJ, Galderisi S, Balottin U, Ricca V and McGuire P (2017) Deconstructing vulnerability for psychosis: meta-analysis of environmental risk factors for psychosis in subjects at ultra high-risk. European Psychiatry 40, 65-75.

Lee TY, Kim SN, Correll CU, Byun MS, Kim E, Jang JH, Kang DH, Yun JY and Kwon JS (2014) Symptomatic and functional remission of subjects at clinical high risk for psychosis: a 2-year naturalistic observational study. Schizophrenia Research 156, 266-271.
Lin A, Wood SJ, Nelson B, Beavan A, McGorry P and Yung AR (2015) Outcomes of nontransitioned cases in a sample at ultra-high risk for psychosis. American Journal of Psychiatry 172, 249-258.

McGlashan T, Walsh BC and Woods SW (2010) The Psychosis Risk Syndrome: Handbook for Diagnosis and Follow-up. New York: Oxford University Press.

McGorry PD (2015) Early intervention in psychosis: obvious, effective, overdue. Journal of Nervous and Mental Disease 203, 310-318.

Nelson B, Yuen HP, Wood SJ, Lin A, Spiliotacopoulos D, Bruxner A, Broussard C, Simmons M, Foley DL, Brewer WJ, Francey SM, Amminger GP, Thompson A, McGorry PD and Yung AR (2013) Long-term follow-up of a group at ultra high risk ('Prodromal') for psychosis: the PACE 400 study. JAMA Psychiatry 70, 793-802.

Nuechterlein KH, Green MF, Kern RS, Baade LE, Barch DM, Cohen JD, Essock S, Fenton WS, Frese III FJ, Gold JM, Goldberg T, Heaton RK, Keefe RS, Kraemer H, Mesholam-Gately R, Seidman LJ, Stover E, Weinberger DR, Young AS, Zalcman S and Marder SR (2008) The MATRICS consensus cognitive battery, part 1: test selection, reliability, and validity. American Journal of Psychiatry 165, 203-213.

Riecher-Rossler A and Studerus E (2017) Prediction of conversion to psychosis in individuals with an at-risk mental state: a brief update on recent developments. Current Opinion in Psychiatry 30, 209-219.

Rutigliano G, Valmaggia L, Landi P, Frascarelli M, Cappucciati M, Sear V, Rocchetti M, De MA, Jones C, Palombini E, McGuire P and Fusar-Poli P (2016) Persistence or recurrence of non-psychotic comorbid mental disorders associated with 6-year poor functional outcomes in patients at ultra high risk for psychosis. Journal of Affective Disorders 203, 101-110.

Saleem MM, Stowkowy J, Cadenhead KS, Cannon TD, Cornblatt BA, McGlashan TH, Perkins DO, Seidman LJ, Tsuang MT, Walker EF, Woods SW and Addington J (2013) Perceived discrimination in those at clinical high risk for psychosis. Early Intervention in Psychiatry 8, 77-81.

Seidman LJ, Shapiro DI, Stone WS, Woodberry KA, Ronzio A, Cornblatt BA, Addington J, Bearden CE, Cadenhead KS, Cannon TD, Mathalon DH, McGlashan TH, Perkins DO, Tsuang MT, Walker EF and Woods SW (2016) Association of neurocognition with transition to psychosis: baseline functioning in the second phase of the North American prodrome longitudinal study. JAMA Psychiatry 73, $1239-1248$

Simon AE, Borgwardt S, Riecher-Rossler A, Velthorst E, de HL and Fusar-Poli P (2013) Moving beyond transition outcomes: meta-analysis of remission rates in individuals at high clinical risk for psychosis. Psychiatry Research 209, 266-272.

Stowkowy J, Liu L, Cadenhead KS, Cannon TD, Cornblatt BA, McGlashan TH, Perkins DO, Seidman LJ, Tsuang MT, Walker EF, Woods SW, Bearden CE, Mathalon DH and Addington J (2016) Early traumatic experiences, perceived discrimination and conversion to psychosis in those at clinical high risk for psychosis. Social Psychiatry and Psychiatric Epidemiology 51, 497-503.

Stowkowy J, Liu L, Cadenhead KS, Tsuang MT, Cannon TD, Cornblatt BA, McGlashan TH, Woods SW, Perkins DO, Seidman LJ, Walker EF, Bearden CE, Mathalon DH and Addington J (2017) Exploration of clinical high-risk dropouts. Schizophrenia Research 195, 579-580.

van OJ and Guloksuz S (2017) A critique of the 'ultra-high risk' and 'transition' paradigm. World Psychiatry 16, 200-206.

van Os J, Linscott RJ, Myin-Germeys I, Delespaul P and Krabbendam L (2009) A systematic review and meta-analysis of the psychosis continuum: evidence for a psychosis proneness-persistence-impairment model of psychotic disorder. Psychological Medicine 39, 179-195.

Webb JR, Addington J, Perkins DO, Bearden CE, Cadenhead KS, Cannon TD, Cornblatt BA, Heinssen RK, Seidman LJ, Tarbox SI, Tsuang MT, Walker EF, McGlashan TH and Woods SW (2015) Specificity of incident diagnostic outcomes in patients at clinical high risk for psychosis. Schizophrenia Bulletin 41, 1066-1075.

Woods SW, Powers III AR, Taylor JH, Davidson CA, Johannesen JK, Addington J, Perkins DO, Bearden CE, Cadenhead KS, Cannon TD, Cornblatt BA, Seidman LJ, Tsuang MT, Walker EF and McGlashan TH (2018) Lack of diagnostic pluripotentiality in patients at clinical high risk for psychosis: specificity of comorbidity persistence and search for pluripotential subgroups. Schizophrenia Bulletin 44, 254-263. 